\title{
Infant-Mother Attachment of Internationally Adopted Children in the Netherlands
}

\author{
Femmie Juffer and Lizette G. Rosenboom \\ Utrecht University, the Netherlands
}

\begin{abstract}
In the Netherlands, 80 mothers and their infants, adopted from Sri Lanka, South Korea and Colombia, were observed at home at 6 and 12 months to rate the adoptive mother's sensitivity, and in the Strange Situation at 12 and 18 months to assess the infant-mother attachment relationship. All inter-racially adopted infants were placed before the age of 6 months, with a mean age of 11 weeks, in adoptive families with or without biological children. Coded with Ainsworth's classification scheme the results reveal 74\% secure attachment relationships, a percentage comparable to that of normative studies. The results indicate no differences regarding the child's country of origin, or the (non)presence of biological children. The results contradict findings from a study that revealed an over-representation of insecure infant-mother attachment relationships in a sample of American mothers with an interracially adopted infant. In the current study the adoptive mother's sensitivity seems comparable to the sensitivity of nonadoptive mothers, a finding that concurs with the attachment results. It is suggested that the outcomes in this study may be partly explained by the fact that these infants were placed for adoption at a rather young age, with relatively favourable circumstances prior to the placement. This may well indicate that adoption placement per se, without the cumulative effects of understimulation and lack of personal affection that older placed children often experience in institutions, does not inevitably lead to a disturbed parent-infant relationship.
\end{abstract}

In the Netherlands 21,000 children have been adopted internationally since the phenomenon of inter-country adoption came into being in the 1970 s. It concerns predominantly inter-racial adoptions, with children from Asia,

Requests for reprints should be sent to Femmie Juffer, Centre for Adoption Studies and Counselling, Utrecht University, Heidelberglaan 1, 3584 CS Utrecht, The Netherlands.

The research reported in this paper was supported by the Dutch Ministry of Education, and the Praeventiefondsin The Hague. The authors wish to thank Isolde Andoetoe, Lieke Metman, and Aukje Oldeman for their help in data collection and scoring. Present affiliations of the first author: Researcher at the Centre for Adoption Studies and Counselling, Utrecht University, and Assistant-Professor at the Centre for Child and Family Studies, Leiden University. Affiliation of the second author until 1994: Researcher at the Centre for Adoption Studies and Counselling, Utrecht University. 
Africa, or South America placed in white Dutch families. Children are adopted from birth until 6 years of age (an exception is made for older siblings accompanying younger children).

\section{Effects of the Adoption Experience}

The development of adoptees has been the focus of several studies. On the basis of a meta-analysis that involved 66 studies on the psychological adjustment of adopted children and adolescents, Wierzbicki (1993) concludes that: (1) adoptees are over-represented in clinical populations; (2) adopted adolescents have more externalising problems than nonadoptees; and (3) adopted children have more academic problems than nonadopted children. Because many studies in this meta-analysis concern locally adopted children of the same race, we do not know whether these conclusions can be generalised to internationally, inter-racially adopted children. In this case, children not only have to deal with their adoption status, but also with their racially different appearance, and with the fact that they came from a country that is culturally different from the country they live in. Studies that involve international adoptees (Hoksbergen, Juffer, \& Waardenburg, 1987; Verhulst, Althus, \& Versluis-den Bieman, 1990; for overviews, see: Silverman \& Feigelman, 1990; Tizard, 1991) indicate that although the large majority of the adoptees develop well, some serious emotional and behavioural problems occur in part of the adoptive families. Especially in adolescence, a higher incidence of problems is found in adoptive families as compared to biological families (Hoksbergen, 1995; Hoksbergen, Spaan, \& Waardenburg, 1988; Verhulst et al., 1990). In addition, Dutch studies (Geerars, 't Hart, \& Hoksbergen, 1991; Hoksbergen, 1995; Hoksbergen et al., 1988) found that adoptive families with biological children appear more at risk for adoption disruption and behavioural problems than adoptive families without biological children. On the basis of his clinical work Schneider (1995) also emphasises that children from adoptive families without biological children are less problematic than adoptees from families with biological children.

To date, the state of the art in inter-country adoption research is not conclusive as to the origins of the reported problems. In most (retrospective) studies on the long-term adjustment of internationally adopted children the variables that may have contributed to the later maladjustment are entangled. Although all adopted children experience a major separation from their primary attachment figures and placement with new attachment figures in the adoptive family, only some of the adopted children, and in a varying degree, experience neglect or abuse, lack of personal attention in an institution, recurrent changes in parental figures, unstable care in an understimulating or affectionless environment, etc. From this complex 
background, it is difficult to disentangle the effect of the adoption experience per se, which is in essence a process of separation and re-attaching. To date, we do not know whether early attachment problems or attachment disorders (Zeanah, Mammen, \& Lieberman, 1993) in the adoptive family contribute to the problems that occur later in life.

\section{Attachment in Adoptive Families}

In attachment theory much attention is paid to the negative effects of separations from primary attachment figures on the well-being of children (Bowlby, 1973). It is recognised, however, that the negative consequences of separations can be decreased when the child is provided with adequate and personal care (e.g. by loving foster parents, Robertson \& Robertson, 1989). In adoption this is a crucial issue: Is the child able to overcome the consequences of the separation experience and attach to new parents, and are the adoptive parents able to bond to an unrelated child without the experience of pregnancy, giving birth, and experiences in initial communication (Papousek \& Papousek, 1992)? In earlier studies (Tizard \& Rees, 1975; Yarrow \& Goodwin, 1973) the parent-child relationship in adoptive families has been studied in an exploratory, descriptive way. Yarrow and Goodwin (1973) found that infants placed for adoption under 6 months of age showed apathetic withdrawn behaviour towards the new mother, or clung to her and cried inconsolably whenever she went out of their sight. Infants placed after 6 months showed rejection of the new mother and excessive clinging to her, or severe withdrawal.

Because attachment theory provides a conceptual framework (Bowlby, 1982) and a paradigm to assess the quality of the child-parent attachment relationship, the Strange Situation (Ainsworth, Blehar, Waters, \& Wall, 1978), attachment in adoptive families can be observed with more scrutiny. From their behaviour in the Strange Situation children can be classified as securely or insecurely attached. Secure children are able to use their parent as a secure base: Seeking and finding comfort when distressed, and otherwise exploring the world. Insecure children do not seek or find comfort in stressful situations. Ainsworth et al. (1978) also related the parent's ability to respond adequately to the child's signals, sensitive responsiveness, to the quality of the attachment relationship. In the current study we want to examine the infant-parent attachment relationship in adoptive families: Are adopted children able to use the adoptive parent as a secure base, and are adoptive parents sensitive and responsive enough to the needs of the child to become a secure base? Because we will study this issue in families that adopted young infants, we may discover the contribution of the adoption placement per se on attachment, without the interfering variables of prolonged neglect or deprivation. Furthermore, we will study this issue in 
adoptive families with and without biological children to examine whether the problems that occur later in life in adoptive families with biological children (partly) originate in early attachment problems.

Recently, the child-parent attachment relationship in adoptive families has been studied at preschool age. Marcovitch et al. (1995) found in their sample of Romanian adoptees less securely attached children than normally expected. Also, Romanian adoptees showed more indiscriminately friendly behaviour than nonadopted peers (Chisholm \& Ames, 1995). Only one study examined attachment in adoptive families in infancy: Singer, Brodzinsky, Ramsay, Steir, and Waters (1985) studied attachment patterns in a sample of American mothers with their intra-racially or inter-racially adopted infant. The group of inter-racially adopted infants resembles our group of internationally adopted children the best. Singer et al. (1985) found that 11 of $19(58 \%)$ inter-racial adoptees were insecurely attached, as compared to 7 of 27 (26\%) nonadoptees. Compared to other studies (Van IJzendoorn, Goldberg, Kroonenberg, \& Frenkel, 1992; Van IJzendoorn \& Kroonenberg, 1988) the inter-racially adopted group shows an overrepresentation of insecure attachment relationships.

\section{METHOD}

\section{Participants}

For the purpose of this paper, 80 mother-infant dyads were selected from two intervention studies (Juffer, Rosenboom, Hoksbergen, RiksenWalraven, \& Kohnstamm, in press) involving 90 adoptive families without biological children (Juffer, 1993) and 70 adoptive families with biological children (Rosenboom, 1994). Only those groups who did not receive intervention, a control group $(n=60)$ and a post-test-only group $(n=20)$, were selected. The control group consisted of first or second adopted children; the post-test-only group consisted of second adopted children (the ordinal position of the adopted children varied from 1 to 5). Families were recruited through Dutch adoption agencies. Nonresponse rate in the original intervention studies varied between $9 \%$ and $20 \%$. The children were adopted from Sri Lanka (40), South Korea (23), and Colombia (17). The background of the children is different for the three countries of origin. In Sri Lanka, babies are taken care of by their biological mother until they are handed over to the adoptive parents at the sitting of the court where the adoption is legislated, so the infant experiences one major separation. In Korea and Colombia, babies stay at a children's home after the mother has relinquished them, and sometimes go to a foster home as well before the adoption placement. These children experience two or three separations. Many children are the offspring of unmarried women. In South Korea, the child of an unmarried woman will not be registered in the family books and 
hence does not "exist". In Sri Lanka and Colombia the family's poverty is an additional motive to relinquish in many cases. In South Korea, poverty is a less important factor. Adoption procedures differ for the involved countries: Korean children are escorted to the Netherlands whereas the adoptive parents travel to Sri Lanka or Colombia to meet their child and take him/her home themselves.

Table 1 summarises some relevant child characteristics for the children from Sri Lanka, South Korea, and Colombia. The three groups differ with respect to the child's health situation, the incidence of prematurity, and the age of arrival. As Table 1 shows, relatively many children from Sri Lanka arrived with health problems (e.g. symptoms of undernourishment or dehydration, anaemia, paratyphoid) as compared to the other two countries $\left[\chi^{2}(2, N=80)=14.06, P<.001\right]$. There also is an over-representation of premature infants from South Korea $\left[\chi^{2}(2, N=77)=14.09, P<.001\right]$. Finally, the infants from Sri Lanka were significantly younger on arrival than the babies from Colombia or Korea $[F(2,74)=41.71, P<.001]$.

The parents can be distinguished with respect to the type of family: Adoptive families without biological children and adoptive families with biological children. In Table 2, parent and family characteristics are summarised for these two family types. The groups differ with respect to several variables. As Table 2 shows, the two groups differ regarding the incidence of infertility $\left[\chi^{2}(1, N=80)=22.57, P<.001\right]$. Most adoptive families without biological children adopt because they wish to raise children and build a family (internal motivation, Hoksbergen et al., 1987),

\section{TABLE 1}

Child Characteristics by the Child's Country of Origin

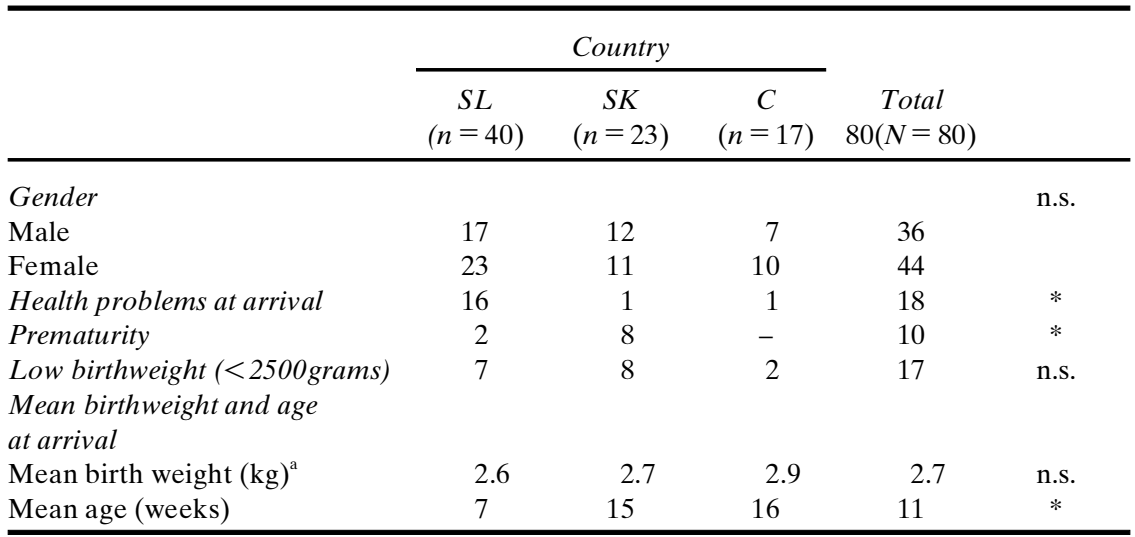

Note: SL, Sri Lanka; SK, South Korea; C, Colombia. ${ }^{*} P<.001$; n.s., not significant.

${ }^{a}$ Birthweight is known for 59 infants. 
TABLE 2

Family Characteristics in Adoptive Families Without and With Biological Children

\begin{tabular}{ccc}
\multicolumn{2}{c}{ Biological } & Children \\
No & Yes & Total \\
$(n=57)$ & $(n=23)$ & $80(N=80)$
\end{tabular}

Educational level of the mother

Low

Middle

High

Educational level of the father

Low

Middle

High

Employment of mother outside home

$>10$ hours/week

$<10$ hours/week

Not working outside home

Motivation for adoption

Mainly internal reasons

Mainly external reasons

Internal and external reasons

Primary or secondary infertility

No

Yes

Adopted child is:

First child

Second child

Third child

Fourth or fifth child

Adopted child is:

First adopted child

Second adopted child

$\begin{array}{rrr}10 & 6 & 16 \\ 36 & 12 & 48 \\ 11 & 5 & 16 \\ & & \\ 10 & 4 & 14 \\ 22 & 12 & 34 \\ 25 & 7 & 32 \\ & & \\ 19 & 3 & 22 \\ 17 & 20 & 37 \\ 20 & - & 20 \\ & & \\ 42 & 7 & 49 \\ 5 & 14 & 19 \\ 10 & 2 & 12 \\ & & \\ 6 & 15 & 21 \\ 51 & 8 & 59 \\ & & \\ 30 & - & 30 \\ 26 & 7 & 33 \\ 1^{\mathrm{a}} & 11 & 12 \\ - & 5 & 5 \\ & & 50 \\ 30 & 20 & \\ 27^{\mathrm{a}} & 3 & \end{array}$

n.s.

16

48

16

14

34

32

22

37

20

49

19

12

21

59

30

33

12

5

50

30

Note: $* P<.001 ;$ n.s., not significant.

${ }^{a}$ In one case the child is the second internationally adopted child in a family with one locally and two internationally adopted children.

whereas most adoptive families with biological children adopt from an idealistic point of view: To give a deprived child a future (external motivation) $\left[\chi^{2}(2, N=80)=24.59, P<.001\right]$. The two groups have different patterns of the mother's employment outside the home $\left[\chi^{2}(2, N=79)=\right.$ $21.92, P<.001]$. Due to measures of group selection the children in the two family types differ with respect to the child's ordinal position in the family $\left[\chi^{2}(3, N=80)=48.60, P<.001\right]$, and the position of being the first or second adopted child $\left[\chi^{2}(1, N=80)=6.84, P<.01\right]$.

The families with or without biological children are not different with respect to the relevant child characteristics, with the exception of the 
country of origin. In families without biological children, most children $(n=34)$ came from Sri Lanka, 12 from Korea, and 11 from Colombia, whereas in families with biological children, 11 infants came from Korea, 6 from Sri Lanka, and 6 from Colombia $\left[\chi^{2}(2, N=80)=8.13, P<.05\right]$.

In preliminary analyses the post-test-only group $(n=20)$ was compared to the control group that participated in pre-tests and post-tests $(n=60)$. In the post-test-only group, the age of the child's arrival was higher than in the control group $[M=16.00$ weeks, $\mathrm{SD}=6.16$ and $M=9.74$ weeks, $\mathrm{SD}=4.64$, respectively; $t(75)=4.76, P<.001]$. The post-test-only group did not differ from the control group with respect to parent or family characteristics, other than the variables related to group selection.

\section{Procedure}

For 60 families (the control group), the study began when their adopted baby was 6 months of age. In three home visits at 6 months the families participated in an interview (with questions about their motivation for adoption, the adoption procedure, and the post-adoption adjustment of the baby), the mother and her child were videotaped in a free-play situation in order to rate the mother's sensitive responsiveness, and the infants participated in two tests measuring their competence (these are not described). At 9 months, in one home visit, one competence measure was repeated, and mother-infant interaction was videotaped (the latter for reasons of comparability to the intervention groups). In one home visit at 12 months, the competence measures were repeated, and the mother and infant were again videotaped in a free-play situation. At 12 months and at 18 months, the mother and child were invited to visit the laboratory, where the quality of infant-mother attachment was assessed.

For 20 families (the post-test-only group) the study started when their child was 12 months of age. They participated in the same procedures at 12 and at 18 months as the control group.

\section{Measures}

Infant-Mother Attachment. To assess individual differences in the quality of the infant-mother attachment relationship Ainsworth's Strange Situation paradigm and guidelines for scoring (Ainsworth et al., 1978) were used at 12 and at 18 months. In this procedure it is observed how the child reacts to the arrival of a stranger and two short separations from the mother. On the basis of videotape recordings of their Strange Situation behaviour infants are assigned to one of three attachment groups: (A) insecure avoidant, (B) secure, or (C) insecure ambivalent. After a short separation, secure infants interact positively with their mother, they seek contact or proximity, and they are comforted by their mother. Avoidant infants turn, look, or move away from the mother or ignore her on reunion. Ambivalent 
infants show a mixture of contact-seeking and resistant behaviour, and are difficult to comfort following stress. For the analyses the insecure avoidant (A) children were combined with the insecure ambivalent (C) children, because the number of ambivalent children was small.

The observers were trained in rating Strange Situation behaviour by Dr D.C. van den Boom (Leiden University, the Netherlands), who was trained by Dr L.A. Sroufe. In the original studies each videotape was coded twice by different coders. It was ensured that a coder did not visit the involved dyad at home. Inter-rater reliability for two pairs of two coders varied from .80 to 1.0 (Cohen's kappas) in the original intervention studies (Juffer, 1993; Rosenboom, 1994). In the case where a different classification was given, consensus was reached after discussion. (At 18 months, one of the Strange Situation classifications is missing.)

Sensitivity. The rating scale "Sensitivity" (Ainsworth, Bell, \& Stayton, 1974) provides a measure to assess individual differences in the mother's sensitive responsiveness: The ability to observe and respond promptly and adequately to the signals of the baby. This 9-point rating scale has been widely used in attachment research. In Ainsworth's well-known Baltimore study (Ainsworth et al., 1978), a strong association was found between sensitivity and quality of attachment, indicating that mothers who responded sensitively to their baby's cues at home had more often a securely attached infant than less sensitive mothers.

The mother and her infant were videotaped at home in a free-play situation during 8 minutes at 6 and 12 months. The infant was seated in front of a low table while the mother was sitting next to the baby. The dyad was provided with a transparent box with 10 attractive toys in it. The mother was instructed to play with her baby the way she usually played. Afterwards, the videotapes were scored with the Sensitivity rating scale. It was ensured that the coders had not visited the mothers they observed. In Rosenboom's study (1994), each videotape was scored by two coders, inter-rater reliability was .75 (Cohen's kappa); consensus was reached through conferencing. In Juffer's study (1993), the inter-rater reliability varied between .89 and 1.0 (Cohen's kappas).

\section{RESULTS}

Infant-Mother Attachment

Testing effects. To exclude the possibility that the distribution secure versus insecure attachment in our adoption group is influenced by the assessments at 6 and 9 months, we compare the group that received pre-tests, the control group $(n=60)$, with the group that did not receive pre-tests, the 
post-test-only group $(n=20)$. No difference was found in the distributions secure versus insecure infant-mother attachment relationships. In the control group, 45 of 60 children are securely attached at 12 and 18 months, in the post-test-only group, 14 of 20 children at 12 months and 14 of 19 children, at 18 months [ 12 months: $\chi^{2}(1, N=80)=0.02$, n.s.; 18 months: $\chi^{2}(1, N=79)$ $=0.00$, n.s.]. We conclude that the earlier assessments did not affect the quality of infant-mother attachment.

Patterns of attachment and stability. Table 3 shows the distribution of patterns of attachment at 12 and 18 months. In contrast to Singer et al. (1985), the current study does not reveal an over-representation of insecure infant-mother attachment relationships. The percentage of secure attachment in our sample ( $74 \%$ at 12 months and $75 \%$ at 18 months) is not lower than the percentage found in normative studies (e.g. $68 \%$ secure attachment in pooled Dutch samples; Van IJzendoorn \& Kroonenberg, 1988). A stability of $68 \%$ (Cohen's kappa .36) was observed in our group: 46 of 58 infants were secure at both 12 and 18 months, 8 of 21 infants remained insecure.

Relations with child characteristics. Table 4 shows that the number of secure versus insecure attachments does not differ for the children adopted from Sri Lanka, South Korea, or Colombia [12 months: $\chi^{2}(2, N=80)=1.68$, n.s.; 18 months: $\chi^{2}(2, N=79)=1.54$, n.s.]. No differences in attachment security were found regarding the variables: health situation at the child's arrival, prematurity, or the age of arrival. Birthweight in general, or a relatively low birthweight $(<2.5 \mathrm{~kg})$ were not associated with attachment security. Both boys and girls were often equally as securely attached [boys at 12/18 months: 25 of $36 / 24$ of 36; girls at 12/18 months: 34 of 44/35 of $43 ; 12$ months: $\chi^{2}(1, N=80)=0.29$, n.s.; 18 months: $\chi^{2}(1, N=79)=1.54$, n.s.].

Relations with family characteristics. Table 5 shows that secure infantmother attachments are developed in adoptive families without biological children as often as in families with biological children [12 months: $\chi^{2}(1$, $N=80)=0.09$, n.s.; 18 months: $\chi^{2}(1, N=79)=0.00$, n.s.]. No differences were found regarding the variables: employment of the mother outside the

TABLE 3

Distribution of Attachment Patterns at 12 and 18 months

\begin{tabular}{lccc}
\hline & $\begin{array}{c}A \\
n(\%)\end{array}$ & $\begin{array}{c}B \\
n(\%)\end{array}$ & $\begin{array}{c}C \\
n(\%)\end{array}$ \\
\hline At 12 months & $19(24)$ & $59(74)$ & $2(2)$ \\
At 18 months & $16(20)$ & $59(75)$ & $4(5)$ \\
\hline
\end{tabular}

Note: A, insecure avoidant; B, secure; C, insecure ambivalent.

${ }^{\mathrm{a}}$ One classification is missing. 
TABLE 4

Security of Attachment for Children Adopted from Sri

Lanka, South Korea, and Colombia

\begin{tabular}{lccc}
\hline & \multicolumn{3}{c}{ Country } \\
\cline { 2 - 4 } & $\begin{array}{c}S L \\
(n=40)\end{array}$ & $\begin{array}{c}S K \\
(n=23 / 22)^{\mathrm{a}}\end{array}$ & $\begin{array}{c}C \\
(n=17)\end{array}$ \\
\hline At 12 months & & & \\
Secure & 29 & 19 & 11 \\
Insecure & 11 & 4 & 6 \\
At 18 months & & & \\
Secure & 32 & 16 & 11 \\
Insecure & 8 & 6 & 6 \\
\hline
\end{tabular}

Note: SL, Sri Lanka; SK, South Korea; C, Colombia.

${ }^{a}$ One classification is missing.

home, motivation for adoption, infertility, or ordinal position in the family. Attachment security was neither related to the adoptive mother's educational level nor to the adoptive father's educational level.

\section{Sensitivity}

Testing effects. To exclude the possibility that the mother's sensitive behaviour is affected by the earlier assessments, we compare the control group $(n=60)$ with the post-test-only group $(n=20)$. No difference was found regarding the mother's sensitivity at 12 months [control group: $M=4.8, \mathrm{SD}=1.5$; post-test-only group: $M=4.7 ; \mathrm{SD}=1.6 ; t(78)=0.29$, n.s.]. We conclude that the adoptive mother's sensitivity is not affected by the 6-month and 9-month assessments.

\section{TABLE 5}

Security of Attachment for Adoptive Families Without and With Biological Children

\begin{tabular}{lcc}
\hline & \multicolumn{2}{c}{ Biological Children } \\
\cline { 2 - 3 } & $\begin{array}{c}\text { No } \\
(n=57)\end{array}$ & $\begin{array}{c}\text { Yes } \\
(n=23 / 22)^{\mathrm{a}}\end{array}$ \\
\hline At 12 months & & \\
Secure & 41 & 18 \\
Insecure & 16 & 5 \\
At 18 months & & \\
Secure & 43 & 16 \\
Insecure & 14 & 6 \\
\hline
\end{tabular}

${ }^{\mathrm{a}}$ One classification is missing. 
The adoptive mother's sensitivity. At 6 months, a mean rating of 5.0 $(n=60 ; \mathrm{SD}=1.6)$ and at 12 months, a mean rating of $4.8(n=80, \mathrm{SD}=1.5)$ was found in the current study. From the tables in Ainsworth et al.'s study (1978, p. 145) we computed a mean rating of $4.7(n=23$; observed between 9 and 12 months). From this comparison, it seems that the adoptive mother's sensitivity is not lower than the biological mother's sensitivity.

Relations with child and family characteristics. At 12 months, adoptive mothers without biological children were rated as more sensitive than adoptive mothers with children of their own $[M=5.1, \mathrm{SD}=1.6$ and $M=4.2$, $\mathrm{SD}=1.3$, respectively, $t(75)=2.38, P<.05]$. However, at the 6 -month assessment the ratings of these two groups did not differ significantly $[M=5.1, \mathrm{SD}=1.5$ and $M=4.5, \mathrm{SF}=1.8$, respectively, $t(55)=1.41, \mathrm{n} . \mathrm{s}$. $]$. No associations or differences were found regarding the other relevant child and family characteristics.

Association with attachment and stability. No significant relations were found between the mothers' sensitivity and security of attachment (correlations $<.19$ ). Regarding the stability of the mother's sensitivity between 6 and 12 months, a correlation of .27 was found $(n=60 ; P<.05)$.

\section{DISCUSSION}

In a group of 80 mothers with infants internationally adopted from Sri Lanka, South Korea, or Colombia, we found as many secure infant-parent attachment relationships as normally expected. Another finding that concurs with the attachment outcomes is that the adoptive mother's sensitivity to her baby's cues does not seem to deviate from nonadoptive mothers. From these results we conclude that adopted infants appear to be able to use their new parents as a secure base, and also, that adoptive parents appear to be sensitive enough to the needs of their adopted baby to become a secure base. On one hand, these results may be related to the rather young age of adoption placement of this group: 11 weeks. At this age babies are supposed to be in the "attachment-in-the-making" phase, whereas after 6 months they are in the "clear-cut attachment" phase (Bowlby, 1982). Probably, babies may redirect and reorganise their attachment behaviour with relative ease when a stable attachment relationship has not yet been developed (Portello, 1993; Yarrow \& Goodwin, 1973). On the other hand, the results may be partly explained by the relatively favourable circumstances prior to the adoption placement. The infants from Sri Lanka experienced only one separation and received personal care from their biological mother. The South Korean and Colombian infants experienced two or three separations, and were taken care of by professional caregivers, guided by a Dutch adoption organisation. This brings us to the conclusion that the adoption placement per se, without the cumulative effects of understimulation and lack of personal affection that older placed children 
often experience in an institution, does not inevitably lead to a disturbed infant-parent attachment relationship.

The current study does not reveal associations between the child's age of adoption placement and (in)security of attachment or (in)sensitivity of the mother. The same is true for the child's country of origin. Although there were profound differences between the infants-for example, the youngest infant was placed at 3 weeks and the oldest at 25 weeks, birthweight varied between 1500 to 3650 grams, 18 infants had health problems, 10 were born prematurely-these differences are not reflected in the quality of the mother-child relationship. These findings and the result that secure attachment relationships appear to develop in families with young adopted children as often as in biological families gives support to the hypothesis that parents may compensate for some of the handicaps their babies experience (Van IJzendoorn et al., 1992), in this case separation(s) and missed experience in initial communication. The sensitivity data in the current study point in the same direction (see also, Ainsworth, 1989).

Of course, our conclusions may not be valid for older placed children (e.g. those over 6 months), or for children who experienced severe deprivation or unstable care. From case studies, Yarrow and Goodwin (1973, p. 1034) suggest that the negative reactions that some older placed children show immediately after adoption placement, such as rejection of the new parent, may trigger off disturbed parent-infant interactions that set the tone for later relationships. Also, recently performed studies (Chisholm \& Ames, 1995; Marcovitch et al., 1995) point to a possible risk with respect to the child-parent attachment relationship of children that experienced deprivation.

Our finding that the distribution of secure-insecure attachment in families with an internationally adopted child, placed under relatively favourable circumstances and at a very young age, does not appear to deviate from the distributions found in normative samples, is based on observations scored with the original ABC classification scheme (Ainsworth et al., 1978). As we did not have the possibility to take into account insecure $\mathrm{D}$ behaviour (disorganised, disoriented behaviour; Main \& Solomon, 1990) we do not know whether this would affect the attachment distribution. At present, we can not exclude the possibility that the number of secure attachments in the current study is in fact lower, which would be the case if some of the children now classified as B, should be classified as D/B. In future studies, it seems important to take into account $\mathrm{D}$ behaviour together with the $\mathrm{ABC}$ classifications. One hypothesis would be that the loss-related experiences of adoptive families may lead to an over-representation of D behaviour. Adoptive couples often have loss experiences on their way to adoption, such as miscarriages, death of a child, unsuccessful efforts with the new reproductive methods, etc. Also, the fact that many couples have to give up 
the idea of ever having a child of their own because of their infertility, could be considered as a loss, which has to be resolved. As Main and Solomon (1990) show, a loss that is not resolved by the parent often leads to the manifestation of D behaviour in the child. Further investigations are needed to examine the validity of our hypothesis.

In attachment theory, the parent's sensitivity is considered as a key determinant of attachment security. Contrary to our expectation and in contrast to Ainsworth et al. (1978), we did not find a significant association between the adoptive mother's sensitivity and the security of infant-mother attachment. This finding may be (partly) explained by the way we measured sensitivity in the current study. In Ainsworth's study, prolonged, naturalistic observations in the home gave the observer the opportunity to observe a wide variety of infant signals, as well as the mother's reactions to each of these signals. In our study, sensitivity was observed in a brief free-play situation at home, which probably restricted the range of infant signals and the following reactions of the mother. It is possible that our observation did not capture crucial elements of the concept of sensitivity, such as the mother's reactions to the child's distress or contact-seeking. Further investigations are needed to study whether or not significant associations are found when the adoptive parent's sensitivity is measured in prolonged, naturalistic observations.

In adoptive families with biological children we found as many securely attached infants as in adoptive families without biological children. It seems that the higher incidence of problems reported later in life in adoptive families with biological children, cannot be explained by early attachment problems. At the 12-month assessment we found that adoptive mothers with biological children are less sensitive than adoptive mothers without biological children. This could be a meaningful finding with respect to the later problems, because less sensitivity to the child's needs could eventually hinder a rich socioemotional development of the child. However, as this result is not consistent-at 6 months the groups do not differ significantly-we have to be careful in drawing conclusions from this. More study is needed to explore this issue.

In order to unravel the aetiology of the later reported socioemotional problems in adoptive families with or without biological children, a longitudinal design seems to be indicated. We hope to do this with our prospective study; at present, all 160 adoptive families that participated in the original intervention studies are being visited at home and school for a follow-up study at the age of 7 years (Rigg-Jansen, Juffer, \& Hoksbergen, 1994). 


\section{REFERENCES}

Ainsworth, M.D.S. (1989). Attachment beyond infancy. American Psychologist, 44, 709-716.

Ainsworth, M.D.S., Bell, S.M., \& Stayton, D.J. (1974). Infant-mother attachment and social development: Socialization as a product of reciprocal responsiveness to signals. In M.P.M. Richards (Ed.), The integration of a child into a social world (pp.99-135). London: Cambridge University Press.

Ainsworth, M.D.S., Blehar, M.C., Waters, E., \& Wall, S. (1978). Patterns of attachment. A psychological study of the Strange Situation. Hillsdale NJ: Lawrence Erlbaum Associates Inc.

Bowlby, J. (1982). Attachment and loss: Vol. 1. Attachment (2nd ed.). New York: Basic Books.

Bowlby, J. (1973). Attachment and loss: Vol. 2. Separation: Anxiety and anger. Harmondsworth, Middlesex: Penguin.

Chisholm, K., \& Ames, E.W. (1995, March). A follow-up study of attachment security and indiscriminately friendly behavior in Romanian adoptees. Poster presented at the Biennial Meeting of the Society for Research in Child Development, Indianapolis.

Geerars, H.C., Hart, H 't, \& Hoksbergen, R.A.C. (1991). Waar ben ik thuis? Geadopteerde adolescenten over adoptie, hun familie, problemen, uithuisplaatsing en toekomstvisie [Where do I belong? What adolescent adoptees think about adoption, their family, problems, adoption disruption, and future plans]. Utrecht: Centre for Adoption Studies and Counselling, Utrecht University, the Netherlands.

Hoksbergen, R.A.C. (1995, March). Adopted children as adolescents. Paper presented at the Biennial Meeting of the Society for Research in Child Development, Indianapolis.

Hoksbergen, R.A.C., Juffer, F., \& Waardenburg, B.C. (1987). Adopted children at home and at school. The integration after eight years of 116 Thai children in the Dutch society. Lisse: Swets \& Zeitlinger.

Hoksbergen, R.A.C., Spaan, J.J.T.M., \& Waardenburg, B.C. (1988). Bittere ervaringen. Uithuisplaatsing van buitenlandse adoptiekinderen [Bitter experiences: Adoption disruption of international adoptees]. Lisse: Swets \& Zeitlinger.

Juffer, F. (1993). Verbonden door adoptie. Een experimenteel onderzoek naar hechting en competentie in gezinnen met een adoptiebaby [Attached through adoption: An experimental study on attachment and competence in families with an adopted baby]. Doctoral dissertation, Utrecht University, the Netherlands.

Juffer, F., Rosenboom, L.G., Hoksbergen, R.A.C., Riksen-Walraven, J.M.A., \& Kohnstamm, G.A. (in press). Attachment and intervention in adoptive families with and without biological children. In W. Koops, J.B. Hoeksma, \& D.C. van den Boom (Eds.), Mother-child interaction and attachment: Old and new perspectives. Amsterdam/London: North Holland.

Main, M., \& Solomon, J. (1990). Procedures for identifying infants as disorganized/ disoriented during the Ainsworth Strange Situation. In M.T. Greenberg, D. Cichetti, \& E.M. Cummings (Eds.), Attachment in the preschool years. Theory, research, and intervention. Chicago: University of Chicago Press.

Marcovitch, S., Goldberg, S., Gold, A., Washington, J., Wasson, C., \& Krekewich, K. (1995, March). Determinants of behavioural problems in internationally adopted Romanian children. Paper presented at the Biennial Meeting of the Society for Research in Child Development, Indianapolis.

Papousek, H., \& Papousek, M. (1992). Beyond emotional bonding: The role of preverbal communication in mental growth and health. Infant Mental Health Journal, 13, 43-52.

Portello, J.Y. (1993). The mother-infant attachment process in adoptive families. Canadian Journal of Counselling, 27, 177-190. 
Rigg-Jansen, E.E., Juffer, F., \& Hoksbergen, R.A.C. (1994, July). Long-term effects at age seven of an early intervention in families with an interracially adopted child: Introduction of the study. Poster presented at the Biennial Meeting of the International Society for the Study of Behavioural Development, Amsterdam.

Robertson, J., \& Robertson, J. (1989) Separation and the very young. London: Free Association Books.

Rosenboom, L.G. (1994). Gemengde gezinnen, gemengde gevoelens? Hechting en competentie van adoptiebaby's in gezinnen met biologisch eigen kinderen [Mixed families, mixed feelings? Attachment and competence of adopted babies in families with biological children]. Doctoral dissertation, Utrecht University, the Netherlands.

Schneider, S. (1995). Adoption and ordinal position. Adoption and Fostering, 19, 21-23.

Silverman, A.R., \& Feigelman, W. (1990). Adjustment in interracial adoptees: An overview. In D.M. Brodzinsky \& M.D. Schechter (Eds.), The psychology of adoption (pp. 187-200). New York: Oxford University Press.

Singer, L.M., Brodzinsky, D.M., Ramsay, D., Steir, M., \& Waters, E. (1985). Mother-infant attachment in adoptive families. Child Development, 56, 1543-1551.

Tizard, B. (1991). Intercountry adoption: A review of the evidence. Journal of Child Psychology and Psychiatry, 32, 743-756.

Tizard, B., \& Rees, J. (1975). The effects of early institutional rearing on the behaviour problems and affectional relationships of four-year-old children. Journal of Child Psychology and Psychiatry, 16, 61-74.

Van IJzendoorn, M.H., Goldberg, S., Kroonenberg, P.M., \& Frenkel, O.J. (1992). The relative effects of maternal and child problems on the quality of attachment: A meta-analysis of attachment in clinical samples. Child Development, 63, 840-858.

Van IJzendoorn, M.H., \& Kroonenberg, P.M. (1988). Cross-cultural patterns of attachment: A meta-analysis of the Strange Situation. Child Development, 59, 147-156.

Verhulst, F., Althus, M., \& Versluis-den Bieman, M. (1990). Problem behaviour in international adoptees: I and II. Journal of the American Academy of Child and Adolescent Psychiatry, 29, 94-103; 104-111.

Wierzbicki, M. (1993). Psychological adjustment of adoptees: a meta-analysis. Journal of Clinical Child Psychology, 22, 447-454.

Yarrow, L.J., \& Goodwin, M.S. (1973). The immediate impact of separation: Reactions of infants to a change in mother figure. In L.J. Stone \& L.B. Murphy (Eds.), The competent infant: Research and commentary (pp. 1032-1040). New York: Basic Books.

Zeanah, C.H., Mammen, O.K., \& Lieberman, A.F. (1993). Disorders of attachment. In C.H. Zeanah (Ed.), Handbook of infant mental health (pp. 332-350). New York: Guilford Press. 